\title{
К ХАРАКТЕРИСТИКЕ БОЛОТНЫХ РУД ЖЕЛЕЗА, ПРИМЕНЯЕМЫХ В ПЕРВОБЫТНОЙ МЕТАЛЛУРГИИ СЕВЕРНОИ ЭСТОНИИ
}

На фоне возрастающего количества археологических данных о добыче первобытным человеком на территории Эстонии потребительского железа из легко доступного местного сырья (Lauringson, 1979), геологический характер и минеральная природа используемых для этих целей руд остались до сих пор вне внимания исследователей. Объясняется это, естественно, тем, что в настоящее время эти рудопроявления уже потеряли практическое значение.

Однако один из авторов данного сообщения (А. Лаурингсон) в последние годы тщательно зарегистрировал и изучил все более или менее известные места проявления первобытной металлургии на территории Северной Эстонии (рис. 1) и собрал в этих местах образцы т. н. болотной руды, являющейся наиболее вероятным сырьем для выплавки местного железа. На это указывают многие названия изученных мест, корни которых явно дают ссылки на древнюю металлодобычу (Раудалу, Рауасоо, Соосепа, Пунасоо и др.; на эст. языке рауд - железо, сепп кузнец, соо - болото).

Осмотр коллекции этих образцов в Институте геологии АН ЭССР (Э. Пиррус) показал, что все эти проявления представлены стяжениями гидроокислов железа, которые по внешнему виду весьма однотипны, - это темно-коричневые комочки или конкреции неправильной формы т.н. болотной руды, образующейся обычно в заболоченных участках местности, в нижнем иллювиальном горизонте почвы или нередко в местах разгрузки источников железоносных грунтовых вод. Масштабы рудопроявлений в этих условиях обычно несущественные рудный пласт имеет мощность обычно не более $4-5$ см, однако площадь его охватывает нередко несколько гектаров. В ходе проведения земледельческих и мелиоративных работ фрагменты этих конкреционных пластов нередко выходят на поверхность в виде легко доступных для сбора покрытий или даже скоплений (Вийтна-Рауасоо).

По структуре ру́ды всех изученных местонахождений весьма близки. В них не наблюдается ни кристаллического строения, ни бобовин, ни оолитов рудного вещества. Основная часть руды представлена выделениями гидроокислов железа двух типов: более крепко сцементированной разновидности темно-бурого или даже фиолетово-черного цвета в виде неправильно построенного каркаса и рыхлой охристо-желтой массы гидроокислов в узлах и порах этого каркаса. Соотношение этих двух разновидностей сильно меняется от куска к куску, а также от одного местонахождения к другому, однако они настолько тесно переплетаются между собою в реальных кусках и связаны, кроме того, плавными переходами, что сепарация их для проведения раздельного анализа практически невозможна. Количественное соотношение обоих 


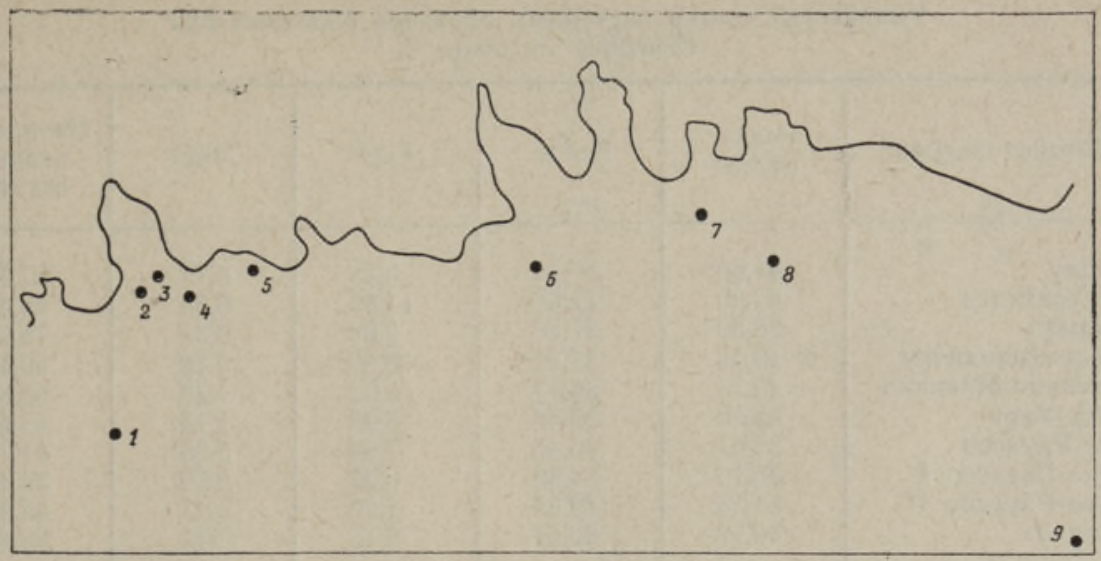

Рис. 1. Местоположение изученных образцов болотных руд. 1 - Раудалу, 2 Клоостриметса, 3 - Пярнамяэ, 4 - Маарду-Крооднору, 5 - Иыэляхтме-Маннива, 6 - Кахала-Уури, 7 - Тыугу-Рауасоо, 8 - Вийтна-Рауасоо, 9 - Тудусилла.

типов рудного вещества определяет и степень цементации образований: наиболее крепкими являются образцы с минимальным содержанием рыхлой охристо-желтой разновидности в пустотах твердого каркаса.

Прямые геологичесқие данные о природе и генезисе этих руд в настоящее время очень скудны, так как в большинстве случаев руда обнаруживается в явно вторичном залегании - в переброшенном и раздробленном в ходе земледельческих работ виде. Однако во всех случаях эти руды залегают не глубже, чем в $0,5-0,6$ м от поверхности земли, являясь тем самым составной частью почвенного профиля. При этом богатые скопления руды наблюдаются в Северной Эстонии одинаково в пределах как карбонатного плато, так и предглинтовой низменности, следовательно, коренной субстрат почвы не играет здесь решающей роли. Более важны, по-видимому, конкретные гидрогеологические условия и запасы органического вещества, мобилизующие минеральное железо и переводящие его в сфере воздействия почвенных процессов в рудные скопления.

Например, в районе Клоостриметса руда располагается на глубине 0,5 м и имеет очень непостоянную мощность от 2 до $20-30$ см, т. е. явно линзовидную структуру. В местонахождении Тыугу-Рауасоо мощность рудного пласта более выдержана, но залегает он и здесь на глубине 0,5 м, охватывая площадь не менее 1,5 га, маркируя контуры небольшого предглинтового родникового болота. Во многих местах участки скопления руды отличаются своеобразной подавленной растительностью, в некоторых местах их скопления являются препятствием для лесонасаждения (Тудусилла). Возможно, что какие-то из этих признаков послужили и важными поисковыми критериями в первобытной металлургин.

По химическому составу (таблица) изученные болотные руды сравнительно близки. Общее содержание $\mathrm{Fe}_{2} \mathrm{O}_{3}$ колеблется в них в пределах $34-55 \%$ и только в одном случае - в сильно опесчаненном образце из Пярнамяэ оно снижается до 20\%. Таким образом, концентрация полезного компонента вполне соответствует содержанию железа в современных рудах, однако она не коррелируется отчетливо с каким-то внешним признаком конкретной руды. Интересным является сравнительно высокое содержание в рудах закисного железа. Так, содержание $\mathrm{Fe}_{2} \mathrm{O}_{3}$ в ряде образцов доходит до $8-14 \%$, что говорит о неполном окислении сконцентрированного железа, следовательно, и о 
Химический состав изученных образцов болотных руд

Северной Эстонии, \%

\begin{tabular}{l|c|c|r|r|c}
\hline \multicolumn{1}{|c|}{ Местонахождение } & $\begin{array}{c}\mathrm{Fe}_{2} \mathrm{O}_{3} \\
\text { общее }\end{array}$ & $\mathrm{Fe}_{2} \mathrm{O}_{3}$ & $\mathrm{FeO}$ & MnO & $\begin{array}{c}\text { Неопреде- } \\
\text { ленный } \\
\text { остаток }\end{array}$ \\
\hline Раудалу & 41,60 & 37,73 & 3,48 & 0,71 & 57,69 \\
Клоостриметса & 52,80 & 37,36 & 13,89 & 0,34 & 46,86 \\
Пярнамяэ & 20,69 & 17,70 & 2,69 & 0,37 & 78,94 \\
Маарду-Крооднору & 49,48 & 37,27 & 10,99 & 0,12 & 50,40 \\
Пыэляхтм-Маннива & 40,18 & 35,71 & 4,02 & 1,49 & 58,33 \\
Кахала-Уури & 34,00 & 29,58 & 3,98 & 1,14 & 64,86 \\
Тыугу-Рауасоо & 55,01 & 46,46 & 7,69 & 3,26 & 41,73 \\
Внйтна-Рауасоо I & 35,10 & 34,69 & 0,37 & 5,50 & 59,40 \\
Вийтна-Рауасоо II & 51,18 & 49,64 & 1,39 & 0,41 & 48,41 \\
Тудусилла & 40,78 & 30,61 & 9,15 & 0,41 & 58,81 \\
& & & & &
\end{tabular}

Примечание. Анализы выполнены сотрудником Института геологии АН ӘССР b. Pooc.

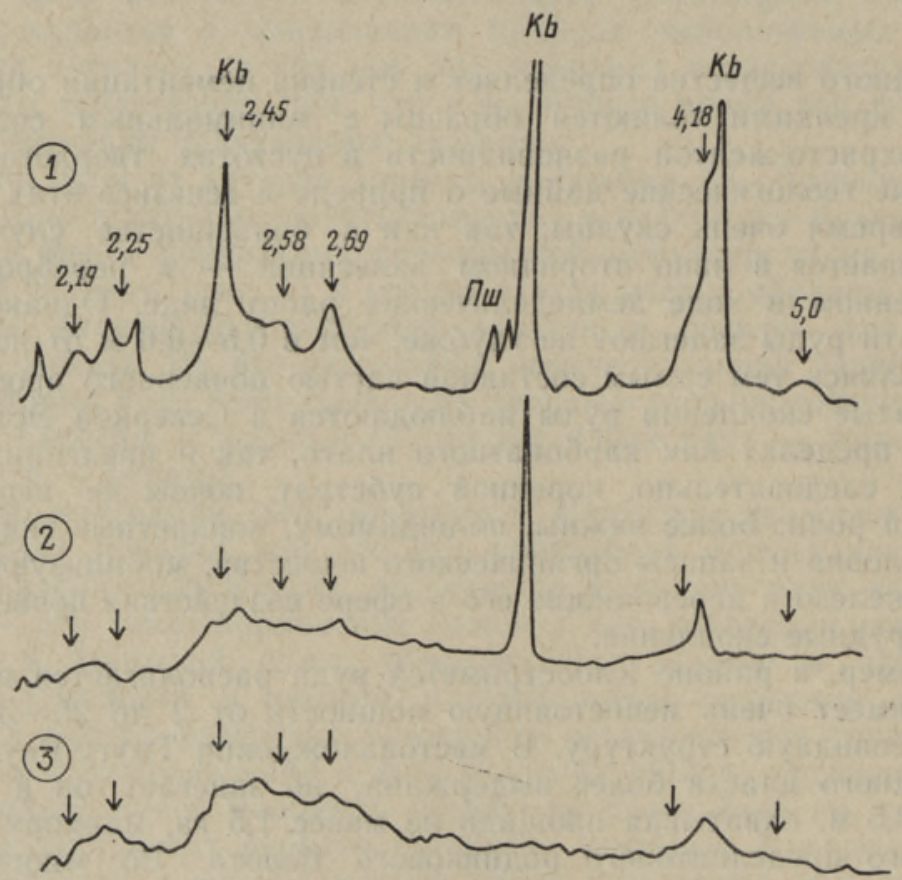

Рис. 2. Дифрактограммы некоторых изученных болотных руд. 1 - Раудалу, 2 Маарду-Кроодиору, 3 - Клоостриметса. Кв - кварц, Пш - полевые шпаты. Стрелочками указаны места основных рефлексов гетита.

большой роли защитных органических коллоидных соединений в процессе миграции железа в этих рудопроявлениях.

В довольно широких пределах в рассматриваемых рудах колеблется содержание $\mathrm{MnO}$ : от следов $(0,12 \%)$ до весьма существенного количества $(5,50 \%)$ в Вийтна-Рауасоо (Pirrus, 1983). Все же характерно, что нанболее высокие содержания $\mathrm{MnO}$ присущи рудным образцам повышенной цементации.

Несколько неожиданные, хотя по существу хорошо согласующиеся с вышеприведенными данными результаты дал рентгеноструктурный анализ образцов, выполненный Т. Калласте в Институте геологии АН 
Рис. 3. Зависимость высоты фона дифрактограммы от содержания железа в руде.

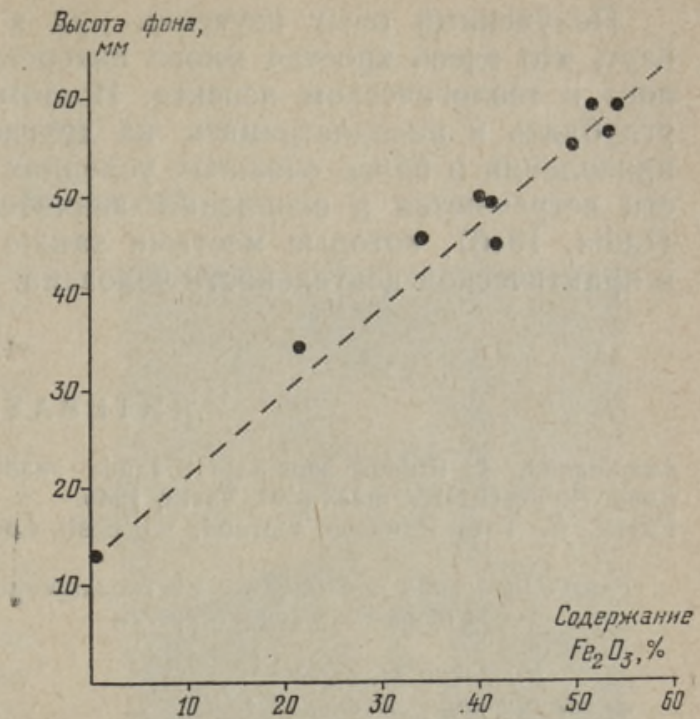

ЭССР. Оказалось, что все рудопроявления имеют рентгеноаморфную форму: лишь изредка на их дифрактограммах обнаруживаются слабые рефлексы гетита, далеко не соответствующие общему содержанию $\mathrm{Fe}_{2} \mathrm{O}_{3}$ в образце (рис. 2). Это говорит о том, что формирование рудных скоплений - процесс явно коллоидальный, а также о том, что образующиеся коллоидные соединения железа очень устойчивы - они не раскристаллизовались даже после длительного лежания на поверхности земли во многих местонахождениях. Рентгеноаморфная форма объясняет также присутствие во многих рудах значительных количеств закисного железа, которое, очевидно, сохранило свою коллондальноорганогенную природу. Следует отметить, что на дифрактограммах не обнаружено и никаких рефлексов, могущих указывать на присутствие кристаллических фаз окисных соединений марганца, которые, по данным химического анализа встречаются иногда в заметных количествах.

Согласуется с рентгеноаморфной природой руд и повышенный фон дифрактограммы. Принимая высоту фона чистого кварцевого песка, снятого в том же режиме, за нулевой, получаем, что все точки измеренных высот фона у рудных образцов показывают отчетливую линеарную зависимость от валового содержания железа (рис. 3). Это дает возможность весьма точно оценить содержание железа в таких образованиях по одним только данным рентгеноструктурного анализа.

Следует также отметить, что отсутствие кристаллической структуры, по всей вероятности, - специфическая черта болотной руды данного типа. Во всяком случае при возникновении других железистых корочек и конкреционных образований, изученных нами рентгенографически в других типах четвертичных отложений, всегда присутствуют и кристаллические фазы соединений железа, главным образом гетит, реже гематит, иногда и сидерит. Это лишний раз свидетельствует о том, что рассматриваемые болотные руды, дающие достаточные скопления для первобытной металлодобычи, формировались в специфических условиях - под защитой органических коллоидов, которые препятствовали обычным минералогенетическим процессам. Эти особенности, конечно, не были решающими для применения именно данной руды в древней металлургии. Определяющими факторами послужили скорее достаточная концентрация металла и доступность этих рудопроявлений сбору. 
Полученный опыт изучения руд в доисторическую эпоху показывает, что здесь кроется много интересного и до сих пор не разгаданного в геологическом аспекте. Поэтому такие исследования полезно углублять и распространять на другие объекты, например на рудопроявления в более сложных условиях Южной Эстонии, где, в частности встречаются и скопления значительной мощности рыхлой охры (Luha, 1946), которые местами также применялись в качестве сырья в практической деятельности человека.

\section{ЛИТ Е РА Т УРА}

Lauringson, A. Kuidas soomaagist rauda saadi. - Eesti Loodus, 3, 1979. Luha, A. Eesti NSV maavarad. Tartu, 1946.

Pirrus, E. Taas Rauasoo sooraud. - Eesti Loodus, 8, 1982, 515-516.

\section{Республиканское объединение «Эстколхозстрой» Управление строительства}

Поступила в редакцию 10/XI 1983

Ннститут геологии

Академии наук Эстонской ССР

\section{A. LAURINGSON, E. PIRRUS}

\section{POHJA-EESTIS IIDSEL RAUASULATAMISEL KASUTATUD SOORAUAMAAKIDE ISELOOMUST}

Teadaolevatest vanadest rauasulatuskohtadest (sellele viitab ka eestikeelne kohanimi) kogutud maagipalad on oma välisilmelt väga sarnased ja pärinevad enamasti 0,5 $0,6 \mathrm{~m}$ sügavuselt maapinnast, markeerides seejuures aga hüdroloogiliselt üsna erinevaid soostumisolusid nii paleosoikumi karbonaatsel lavamaal kui ka klindiesisel tasandikul. Maagipalade keemiline koostis on võrdlemisi püsiv, tähelepanu väärib vaid muutlik $\mathrm{MnO}$ ja sagedane suhteliselt kõrge $\mathrm{FeO}$ sisaldus. Siseehituselt on maagipalad röntgenoamorfsed, mis viitab nende kolloidsele tekkeviisile ja orgaaniliste ainete kaitsvale toimele hilisemate muutuste eest. Röntgenogrammi fooni kõrgus on otseses sōltuvuses proovi rauasisaldusest ja seda võib kasutada analüütilise parameetrina maagi koostise hindamisel.

\section{A. LAURINGSON, E. PIRRUS}

\section{ON THE CHARACTER OF THE BOG-IRON ORES USED FOR ANCIENT IRON-SMELTING IN NORTH ESTONIA}

The ore samples gathered from the ancient iron-smelting places (Fig. 1), the Estonian names of which indicate the corresponding process, look very alike outwardly. The samples come from a depth of $0.5-0.6 \mathrm{~m}$ from the earth surface and characterize different circumstances of embogging, both on the Palaeozoic carbonate plateau, as well as on the bore-clint plain. The chemical composition of ore samples is quite constant (Table), except a variability in the $\mathrm{MnO}$ content and frequently a relatively high content of $\mathrm{FeO}$. The ore samples are inwardly roentgen-amorphous (Fig. 2) due to their colloidal genesis and to the protecting action of organic matter. The height of the foil (background) on the X-ray diffractograms is directly related to the iron content in the samples (Fig. 3) and may be used as an analytical parameter for the estimation of the ore composition. 